\title{
Critical analysis and digital literacy in learning social psychology
}

González-Conde, Joan ${ }^{\text {a }}$ Codina, Nuria ${ }^{\mathrm{a}}$; Valenzuela, Rafael ${ }^{\mathrm{a}}$; and Pestana, Jose Vicente $^{\mathrm{a}}$

${ }^{\mathrm{a} D e p a r t m e n t}$ of Social Psychology and Quantitative Psychology, University of Barcelona, Spain

\begin{abstract}
This paper presents a teaching experience in social psychology learning, aimed at students' acquisition of critical analysis and digital literacy competences at the University of Barcelona. The methodology consisted of asking each student to answer to a socially relevant question, by means of (a) identifying key underlying psychosocial processes and (b) searching for adequate keywords in scientific databases such as PsycNet and Sociological Abstracts, in order to (c) select and critically compare two relevant articles that could answer this question. The acquisition of these competences was assessed with a rubric and related questions in the final exam. Results indicated both the effectiveness of this approach to teach competences in digital literacy and critical analysis through motivating questions, and the translation of these competences in other situations. This approach also showed to be more effective in teaching these ompetences than only giving lectures. This methodology is promising, as it provides an answer to how to give future professionals competences in answering effectively and rigorously to socially relevant problems in the Information Society.
\end{abstract}

Keywords: Critical Analysis; Digital Literacy; Psychology teaching; Motivation; Database usage. 


\section{Introduction}

The acquisition of competences in Critical Analysis (CA) and Digital Literacy (DL) is crucial to work efficiently within the innovation, growth, and social development processes of the Information Society (European Commission, 2016). Higher education has a decisive role in promoting these competences (De Pablos, 2010), as a key agent to teach future professionals how to answer relevant questions for their professional areas, dealing effectively with the exponential increase of available information (Verstak et al., 2014). Nowadays, one of the aims of higher education in social psychology is to give competences in DL and CA to future professionals (Agència per a la Qualitat del Sistema Universitari de Catalunya, 2005). These professional competences are necessary to answer in a rigorous and empirically-grounded way to relevant psychosocial issues such as addictions, social inequality and intercultural and gender conflicts. In this aim, following the principles of self-determination theory (Deci \& Ryan, 1985, 2000), it is fundamental to contemplate the basic needs of the students, regarding their need for perceived control of what they are doing, their independence, autonomy, and self-reliance - all of them being central aspects for student's motivation (Arnone, Reynolds, \& Marshall, 2009; Niemiec \& Ryan, 2009), and classroom management (Babad, 2009).

In relation to these competences, it is usual to work on them independently (e.g. Corral et al., 2015), but it is crucial to work on both competences at the same time, so as to promote the efficiency of the training. The aim of this paper is to present an experience that combines the development of both DL and CA in learning social psychology. This experience corresponds to a $1^{\text {st }}$-year course during the $2^{\text {nd }}$ semester, an it is framed in two on-going projects in teaching innovation at the Faculty of Psychology at the University of Barcelona, which aim to foster these competences in university students during their formation in the degree of psychology. The experience presented here made the students face the task of giving an answer to a question related to current and socially-relevant issues (e.g., the possible influence of videogames on aggressive cognitions). In order to do so, they followed these steps: first, to identify the most appropriate keywords reflecting the underlying psychosocial processes of the issue; second, to use those keywords when looking for articles in two scientific databases (i.e. PsycNET and Sociological Abstracts); thirdly, to use critical and justified criteria to select one article from each database; and lastly, to compare these articles focusing on how the answer they give to the question is complementary, opposed, or converging. Students had to report each step of the process in a paper (around 15 pages), and then they had to make a brief oral presentation (around 10 minutes) to explain their findings to their fellow students. In the next sections, the context and structure of this work is explained. After, its efficacy was evaluated according to the marks obtained by the students at the end of the project, and their ability to respond to specific questions related to CA and DL in the final exam. 


\section{Methodology}

\subsection{Participants}

This project took place in a group of 200 students (158 women and 42 men) in a compulsory course in social psychology, during the second semester of the first year in the degree of psychology, at the Faculty of Psychology at the University of Barcelona, from February to May of 2016. Students gave their consent for the use of the data.

\subsection{Databases}

The scientific databases used by the students during this experience were PsycNET and Sociological Abstracts. Both of them contain academic publications. PsycNET focuses on psychology and related subareas, while Sociological Abstracts's standpoint is sociology. Given the nature of social psychology, and the importance of both disciplines for this area (Codina, 1997; Munne, 1997), it is relevant that the students can search efficiently in any of these databases to give a comprehensive and rich answer.

\subsection{Procedure}

Regarding the structure of the work sessions, during the first session, students were introduced to the objective of this project, the rubric that would be used to assess their performance, and the searching process. During the following two weeks, they had to organize themselves in workteams from 3 to 8 persons each, and each group had to choose a question related to a key social issue from a list previously elaborated by the teachers. This question was a proxy to make students rethink a social issue in psychosocial terms (e.g. attitude change, persuasion, prejudices, or dehumanization), and then the group identified the corresponding keywords to use in their search in PsycNET and Sociological Abstracts. In the second session, the teacher worked on their search results, giving general tips and tools on how to refine their searches (e.g. filters and Booleans), reviewing their keywords, and resolving other additional problems related to how they selected and interpreted the articles. In the following four weeks, they elaborated their written assignment. Two teachers involved directly in the design and evaluation of the project supervised online through e-mails, and presentially through individualized sessions under request. After sending their written assignment, students were given training in oral presentation skills, and after a month they defended their searching process and results in front of the class.

Written assignment structure consisted of 3 sections. In the first section (i.e. introduction), students summarized their searching process, the articles that they found, and the main conclusions they derived. In the second section, students detailed every step of the searching and analysis process. That is, how they identified each keyword and which filters 
were applied for the search,which articles they specified and why, and how each article separately contributed to answer the question. In the third and last section, students compared the two articles and discussed about how they answer altogether to the question. Regarding oral presentations, students were expected to explain briefly their searching process, while focusing specifically on the comparison of the two articles and how they let them answer to their question.

\subsection{Evaluation}

Evaluation consisted of a rubric (see Table 1 in the next section) corresponding to the different parts of the assignment (i.e. identifying keywords, searching appropiately in the databases, selecting one article in each of them, and comparing these two articles to answer the socially relevant question selected in the beginning). The marks in this rubric were given according their performance both in the writing assignment and in the oral presentation. In each item of the rubric, marks ranged from 0 to 2 , according to how the students met the criteria ( $0=$ Not at all; $1=$ Partially; $2=$ Totally $)$.

\section{Findings}

37 works were marked, with a $M=7.67$ ( $S D=1.77) .33$ of them were approved, with a mean of $8.11(S D=1.31)$. These marks were obtained using the aforementioned rubric. As it is shown in Table 1, students showed proficiency in every aspect evaluated in the rubric. It need to be underscored their competence in searching and analysing the articles, and justifying each step they took in the process. The aspect that they had slightly more difficulties with was assessing the strength and weaknesses of using PsycNET and Sociological Abstracts.

Table 1. Rubric and marks.

\begin{tabular}{lccccc}
\hline \multicolumn{1}{c}{ Criteria } & $\begin{array}{c}\text { Weight } \\
\text { (out of 2) }\end{array}$ & Mdn & $M$ & $S D$ \\
\hline $\begin{array}{l}\text { 1. Formal aspects (i.e. text structure, ortography, and APA style } \\
\text { formatting) }\end{array}$ & 0.25 & 3 & 2.7 & 0.7 \\
$\begin{array}{l}\text { 2. Introduction: objective, search terms and method are } \\
\text { explained briefly and concisely }\end{array}$ & 0.25 & 2 & 1.5 & 0.6 \\
3. Search and analysis & & & & \\
3.1. Information in summary tables is properly explained and \\
justified (i.e. keywords' selection, decission processes, and
\end{tabular}


3.1.1. PsycNET

\subsubsection{Sociological Abstracts}

3.2. Summary table contains requested information (i.e. authors, total publications per year, authors' publications per year)

\subsubsection{PsycNET}

\subsubsection{Sociological Abstracts}

3.3. The article selection process is explained and follows established criteria (i.e. its recence, number of publications of the author, times cited).

\subsubsection{PsycNET}

\subsubsection{Sociological Abstracts}

3.4. Article is analysed comparing students's hypothesis and article results.

\subsubsection{PsycNET}

\subsubsection{Sociological Abstracts}

3.5. Strenght and weaknesses of the process are detected.

\subsubsection{PsycNET}

\subsubsection{Sociological Abstracts}

4. Comparative analysis

4.1. Differences and similarities between results are described and analyzed (authors, number of articles, publication years, and total of cites)

4.2. Pros and cons of each database are described according to their adequacy to deepen on the topic of interest.

4.3. Articles are critically compared according to their differences and similarities in answering their hypothesis on the topic of interest.

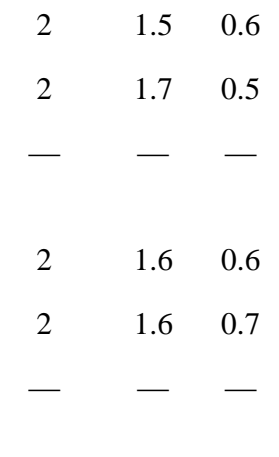

$\begin{array}{lll}2 & 1.6 & 0.6 \\ 2 & 1.5 & 0.6\end{array}$

$\begin{array}{lll}2 & 1.5 & 0.6\end{array}$

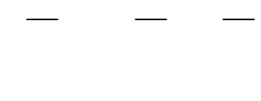

$\begin{array}{lll}2 & 1.5 & 0.5 \\ 2 & 1.6 & 0.6\end{array}$

$-\quad-\quad-$

$\begin{array}{lll}1 & 1.2 & 0.8\end{array}$

$\begin{array}{lll}2 & 1.4 & 0.8\end{array}$

0.5

$2 \quad 1.6 \quad 0.6$

$2 \quad 1.6 \quad 0.6$

$2 \quad 1.6 \quad 0.6$

The impact of this training was evaluated using a set of 5 questions in the final exam. In these questions, the student had to indicate the correct answer to different aspects related to the assignment, such as the usage of Booleans, differences between PsycInfo and SocioFILE, and which conclusions can be extracted given a set of results. Table 2 shows the correlations between the different marks obtained during the course, and for every 
specific part of the final exam (i.e. a part related to the syllabus consisting of 25 questions, and a part related to the assignment consisting of 5 additional questions). According to these findings, the marks in the assignment and the marks in the exam correlate positively. More specifically, it needs to be underscored that assignment marks correlate not only with the specific questions of the exam dealing with CA and DL, but also with questions related to the other content of the syllabus.

Table 2. Pearson correlations between marks in the mid-term exam, in the assignment, in the final exam and in the specific questions ( $n=176$ students)

\begin{tabular}{|c|c|c|c|c|c|c|c|c|}
\hline & & $M$ & $S D$ & 1 & 2 & 3 & 4 & 5 \\
\hline & $\begin{array}{l}\text { Mid-term exam (out of } \\
\text { 2) }\end{array}$ & 1,2 & 0,4 & - & - & - & - & - \\
\hline 2. & Assignment (out of 2) & 1,5 & 0,4 &, 10 & - & - & - & - \\
\hline 3. & $\begin{array}{l}\text { Final Exam: Total (out } \\
\text { of } 6 \text { ) }\end{array}$ & 3,2 & 0,8 &, $40 * * *$ &, $21 * *$ & - & - & - \\
\hline 4. & $\begin{array}{l}\text { Final exam (excluding } \\
\text { assignment-related } \\
\text { questions) (out of } 25 \text { ) }\end{array}$ & 16,7 & 3,2 &, $47 * * *$ &, $43 * * *$ &, $93 * * *$ & - & - \\
\hline 5. & $\begin{array}{l}\text { Final exam (only } \\
\text { assignment-related } \\
\text { questions) (out of 5) }\end{array}$ & 1,3 & 1,1 &,- 02 &, $36 * * *$ &, $26 * * *$ &, $34 * * *$ & - \\
\hline
\end{tabular}

In the final exam, students who did the writing assignment and the oral presentation differed from those who only assisted to the lectures and presentations (see Table 3). Specifically, students who did the writing assignment and the oral presentations obtained better marks both in the questions dealing with CA and DL, and with those dealing with the rest of the content of the syllabus. Therefore, in equal conditions, this method shows to be more effective to foster competences in CA and DL than a mere lecture. 
Table 3. Mean differences in exam marks depending on whether the student did the exam or not

\begin{tabular}{|c|c|c|c|c|c|}
\hline \multirow[b]{2}{*}{ Variable } & \multicolumn{2}{|c|}{$\begin{array}{l}\text { Participants of the } \\
\text { experience }(n=200)\end{array}$} & \multicolumn{2}{|c|}{$\begin{array}{l}\text { Only listening to } \\
\text { lectures }(n=47)\end{array}$} & \multirow[b]{2}{*}{$U$} \\
\hline & $M$ & $S D$ & $M$ & $S D$ & \\
\hline $\begin{array}{l}\text { Final exam (excluding assignment- } \\
\text { related questions) (out of 25) }\end{array}$ & 16 & 4,69 & 2,85 & 5,32 & $516 * * *$ \\
\hline $\begin{array}{l}\text { Final exam (only assignment-related } \\
\text { questions) (out of 5) }\end{array}$ & 1,25 & 1,02 & 0,27 & 0,74 & $2001 * * *$ \\
\hline
\end{tabular}

Note. $U=$ Mann-Whitney’s U. $* * *=\mathrm{p}<.001$

\section{Concluding Remarks}

The metholodogy used in this experience has shown to be successful in combining DL and CA. In particular, the process of answering a socially relevant question, through selecting keywords and analysing scientifical articles from different databases, compelled the students for its experiental aspect. This methodology demands the student to make an abstraction of a social issue considering its underlying psychosocial processes, while the teacher supports the autonomy of the student in every part of the process, a key aspect for promoting their self-determination as shown in other educational contexts (Gillet, Vallerand, \& Lafrenière, 2012). With regard to the problematic of managing information effectively, the usage of tools such as summary tables and filters like cites of the article and most cited authors facilitate the process of selecting the most appropriate author. In addition, these criteria let the teacher and students account for every step in the decision process. Concerning limitations of this intervention, the high demand of face-to-face supervision suggests the need to standardized more the teaching process creating tutorials for every part of the process. Also, another limitation refers to working in big groups. In his experience groups were big, and next applications of this intervention will make them work in pairs. To end with, one of the most prominent difficulties was the lack of students' experience with this kind of task, which made it quite tedious for the students in the first satges, but this situation justifies and gives value to our methodology and learning objectives. In sum, this methodology has taught them effectively competences in DL and CA, through compelling questions that motived them to learn more, and in doing so, this knowledge has shown to be translated to other contexts as in the final exam. Thus, this constitutes a good learning process that may facilitate the ulterior generalization of the competences in CA and DL. This experience offers important insights on how to educate future professionals that need to act efficiently and rigorously in the Information Society. 


\section{References}

Arnone, M.P., Reynolds, R., and Marshall, T. (2009). The Effect of Early Adolescents' Psychological Needs Satisfaction upon Their Perceived Competence in Information Skills and Intrinsic Motivation for Research. School Libraries Worldwide, 15(2), 115134.

Agència per a la Qualitat del Sistema Universitari de Catalunya (2005). Guia per al Disseny d'un Perfil de Formació: el cas de Psicologia. AQU: Barcelona.

Babad, E. (2009). The Social Psychology of the Classroom. New York, NY: Routledge.

Codina, N. (1997). Análisis de la realidad social. Barcelona: PPU.

Corral, M.J., Leiva, D., Gallardo-Pujol, D., Recasens, M., Althen, H., Marqués, I., . . . Álvarez, C. (2015, February). Desenvolupament transversal de la competència informacional al $2 n$ semestre del Grau de Psicologia. Poster session presented at the 8th Meeting of Teachers in Health Sciences, Barcelona. Retrieved from http://hdl.handle.net/2445/65237

Deci, E. L., \& Ryan, R. M. (1985). Intrinsic motivation and self-determination in human behavior. New York, NY: Plenum.

Deci, E. L., \& Ryan, R. M. (2000). The" what" and" why" of goal pursuits: Human needs and the self-determination of behavior. Psychological Inquiry, 11 (4), 227-268.

European Commision (2016). Employment and Social Developments in Europe: Annual Review 2016 (EU Publication No. KE-BD-16-001-EN-N). Retrieved from http://ec.europa.eu/social/main.jsp?catId=738\&langId=en\&pubId=7952

Gillet, N., Vallerand, R.J., \& Lafrenière, M.A. (2012). Intrinsic and extrinsic school motivation as a function of age: the mediating role of autonomy support. Social Psychology of Education, 12, 77-95. doi: 10.1007/s11218-011-9170-2

Munné, F. (1997) Pluralismo teórico y comportamiento social. Psicologia \& Sociedade. Associaçao Brasileira de Psicologia Social - ABRAPSO, 9, 1-2, 31-46.

Niemiec, C.P., \& Ryan, R.M. (2009). Autonomy, competence, and relatedness in the classroom: applying self-determination theory to educational practice. Theory and Research in Education, 7(2), 133-144. doi: 10.1177/1477878509104318

Pablos Pons, J. de. (2010). Universidad y sociedad del conocimiento. Las competencias informacionales y digitales. Revista de Universidad y Sociedad del Conocimiento, 7(2), 6-16. Retrieved from http://hdl.handle.net/10609/2603

Verstak, A., Acharya, A., Suzuki, H., Henderson, S., Iakhiaev, M., Lin, C. C. Y., \& Shetty, N. (2014). On the shoulders of giants: The growing impact of older articles. arXiv preprint arXiv:1411.0275. 